\title{
Erratum to: In vitro induction of mouse meningeal-derived iPS cells into neural-like cells
}

\author{
XU Jing ${ }^{1,2}$, WANG Hao ${ }^{1}$, LIANG Tao ${ }^{1,2}$, CAI XiangSheng ${ }^{1}$, RAO XiuRong ${ }^{1}$, \\ HUANG ZhenBo ${ }^{1} \&$ SHENG GuoQing ${ }^{1 *}$ \\ ${ }^{1}$ Key Laboratory of Regenerative Biology, Laboratory of Stem Cell Therapy, Guangzhou Institute of Biomedicine and Health (GIBH), Chinese \\ Academy of Sciences, Guangzhou 510530, China: \\ ${ }^{2}$ School of Life Sciences, University of Science and Technology of China, Hefei 230026, China
}

Erratum to: CHINESE SCIENCE BULLETIN, May 2011 Vol.56 No.15: 1556-1561

doi: $10.1007 / \mathrm{s} 11434-011-4436-9$

The authors report that incorrect figures were included as Figures 4 and 5 in the original publication of this paper. This error occurred during the figure editing process of the publishing company. This information should have been presented as follows:

Nestin

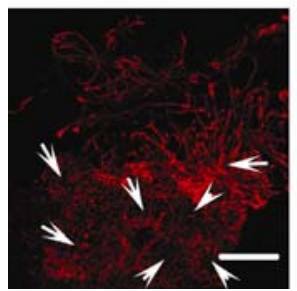

Pax6

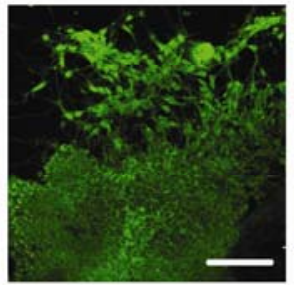

Merge

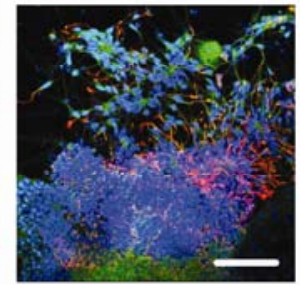

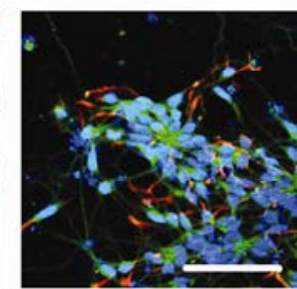

Figure 4 Immunofluorescence analysis revealed that iPSC C5 cells were positive for markers of neural progenitors Pax6 and Nestin at day 6. Arrowhead denotes the formation of neural tube-like rosette structure. Scale bar $=100 \mu \mathrm{m}$.
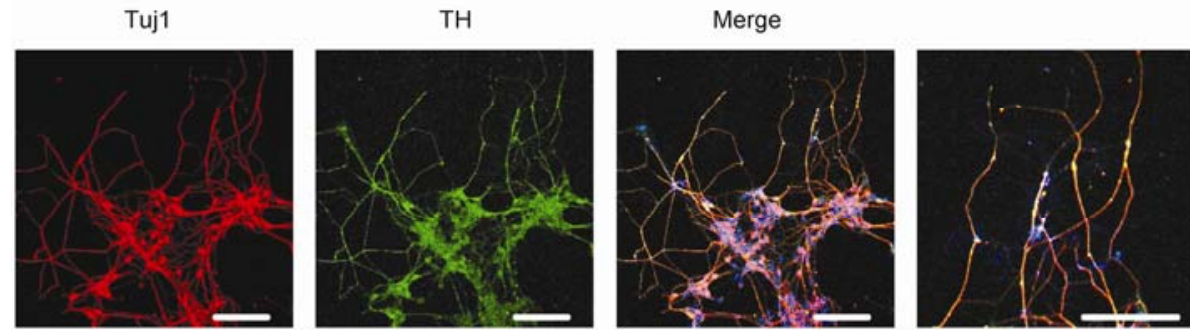

Figure 5 After iPSC C5 cells were cultured in neural differentiation medium for 8-9 d, Tuj1 positive neurons and TH neurons were observed. Scale bar = $100 \mu \mathrm{m}$.

The online version of the original article can be found at http://dx.doi.org/10.1007/s11434-011-4436-9.

Open Access This article is distributed under the terms of the Creative Commons Attribution License which permits any use, distribution, and reproduction in any medium, provided the original author(s) and source are credited. 